\title{
Metodologia singular de gestão de projetos: condição suficiente para a maturidade em gestão de projetos?
}

\author{
Ruy BOUER \\ Marly Monteiro de Carvalho \\ Depto. de Eng. Produção - Escola Politécnica da USP
}

\begin{abstract}
Resumo
O ambiente no qual as empresas atuam hoje está rapidamente tornando-se mais complexo e competitivo. Grandes mudanças tecnológicas e no cenário econômico e de negócios apresentam muitas oportunidades, mas também muitos desafios para as organizações que buscam prosperar de forma sustentável. Projetos têm se constituído em importantes instrumentos para mudanças e desenvolvimento. Modelos de maturidade em projeto têm sido estudados e desenvolvidos para apoiar e dirigir as estratégias de gestão de projetos. A literatura em gestão de projetos destaca que o fato de uma organização possuir uma metodologia singular para a gestão de projetos é um sinal vital do seu grau de maturidade. O presente artigo irá abordar esse tema através de uma revisão dos modelos de maturidade e do estudo de caso na subsidiária brasileira de uma empresa multinacional do segmento de iluminação, combinando uma pesquisa documental da metodologia singular praticada pela empresa com uma pesquisa de campo para avaliar o seu grau de maturidade.
\end{abstract}

Palavras-chave

Gestão de projetos, modelos de maturidade, metodologia singular.

\section{Project management maturity: just a singular methodology is enough?}

\begin{abstract}
The world in which organizations operate today is rapidly becoming more complex than ever before. Major shifts in technology and in the business and economic environment present many opportunities, but also many challenges, to organizations striving to manage and thrive in the midst of great change. Projects have become important instruments for change and development in organizations. Project management maturity models have been studied and developed to sustain and drive project management strategies. The project management literature points out that the fact of one organization possesses a singular methodology to manage projects is a vital signal of maturity in terms of project management. This paper will address this issue through a review of project management maturity models and the presentation of a case study developed in a Brazilian subsidiary of a multinational company from the Lighting segment combining both a desk research of the singular methodology practiced by the company and a field research to evaluate its project maturity.
\end{abstract}

\section{Key words}

Project management, project maturity models, singular methodology. 


\section{INTRODUC̣̃̃O}

Projetos tornaram-se um importante instrumento de mudança e desenvolvimento nas organizações. As principais mudanças organizacionais e as iniciativas para gerar vantagens competitivas têm sido executadas, em sua maior parte, através de projetos organizacionais. Dessa forma, a disciplina gerenciamento de projetos vem ganhando destaque dentro dos modelos de administração e tem-se transformado num fator relevante para prover velocidade, robustez, consistência e excelência operacional na consecução de projetos. Modelos de maturidade em gerenciamento de projetos vêm obtendo notoriedade e cada vez mais são feitos esforços para desenvolver competências organizacionais no gerenciamento de projetos (ANDERSEN \& JESSEN, 2002; CARVALHO et al, 2003; CMM-I, 2002A; CMM-I, 2002B; COOKE-DAVIES \& ARZYMANOW, 2003; GRAY, 2001; KERZNER, 2001; PMI, 2003; WHITE \& FORTUNE, 2002).

A formulação e implementação de uma metodologia singular para o gerenciamento de projetos tem sido apontada pela literatura como uma característica distintiva de organizações já maduras no gerenciamento de projetos. Uma questão interessante que vem à tona é a seguinte: o fato de uma organização possuir uma metodologia singular de gerenciamento de projetos é condição suficiente para defini-la como uma organização madura na disciplina de gerenciamento de projetos? Através de uma revisão da literatura sobre maturidade em projetos e da análise de um caso real de uma empresa multinacional do segmento de iluminação, que possui desenvolvida e implementada uma metodologia singular de gerenciamento de projetos, será possível aprofundar a discussão dessa instigante questão. Metodologia singular, no contexto desse artigo, é definida como uma abordagem particular e customizada de gerenciamento de projetos que envolve princípios, conceitos, ferramentas e um fluxo disciplinado e organizado de estágios para definir, executar, controlar, avaliar e aprimorar os projetos organizacionais.

\section{METODOLOGIA PARA O DESENVOLVIMENTO DO ARTIGO}

Para o desenvolvimento do presente artigo será conduzida, inicialmente, uma revisão da literatura no tocante à investigação e compreensão do conceito de maturidade no gerenciamento de projetos. O ponto de partida dessa análise deverá cobrir aspectos relativos à cultura e à estrutura organizacionais para suportar uma abordagem organizacional para o gerenciamento de projetos. Em seguida, o artigo apresentará uma visão geral dos principais modelos de maturidade em gerenciamento de projetos destacando-se os modelos CMM - Capability Maturity Model, PMMM - Project Management Maturity Model e OPM3 Organizational Project Management Maturity Model (PMI, 2000 e 2001).

Posteriormente, será apresentado um estudo de caso contemplando duas perspectivas: (1) uma pesquisa documental, fonte secundária de dados, através da apresentação da estrutura geral da metodologia singular de gerenciamento de projetos adotada e executada pela empresa selecionada para o estudo de caso, a qual recebe a denominação de MEDIC; (2) uma pesquisa de campo, fonte primária de dados, através do levantamento e avaliação da percepção da gerência das principais áreas da empresa com respeito à maturidade organizacional no gerenciamento de projetos com base no modelo de maturidade Project Management Maturity Model (PMMM).

\section{O AMBIENTE E A ESTRUTURA PARA O GERENCIAMENTO DE PROJETOS}

O dicionário Webster define maturidade como a qualidade ou estado de estar maduro. Quando aplicado o conceito de maturidade a uma organização, refere-se ao estado em que a organização se encontra em perfeitas condições para alcançar seus objetivos. Maturidade em projetos também pode significar que uma organização está perfeitamente condicionada para gerenciar seus projetos. Gray (2001) conduziu uma pesquisa junto a profissionais de gerenciamento de projetos de organizações do Reino Unido para estudar e estabelecer relações entre o clima e o ambiente organizacional para o gerenciamento de projetos e a taxa de sucesso nos resultados proporcionados pelos projetos. Como fruto dessa pesquisa, Gray (2001) concluiu que há um conjunto de fatores e variáveis que influenciam positivamente o sucesso dos projetos e que, em certa extensão, estão relacionados ao estágio de maturidade organizacional no gerenciamento de projetos.

Gray (2001) aponta os seguintes fatores como influenciadores de um clima organizacional positivo para o sucesso no gerenciamento dos projetos: identificação e combate às diversas fontes de ameaça e insegurança dentro da equipe de projeto e da organização como um todo, promoção da satisfação intrínseca e motivação dos integrantes da equipe de projetos, fomento e estímulo ao desenvolvimento de uma cultura particular da equipe de projetos e desenvolvimento de uma cultura organizacional que estimule e valorize o trabalho em equipe e a realização de projetos.

Andersen \& Jessen (2002), baseados em suas pesquisas sobre maturidade organizacional no gerenciamento de projetos, propõem que a maturidade seja medida através de três dimensões: atitude, conhecimento e ação. A 
dimensão atitude contempla os seguintes aspectos: gerenciamento do risco e incerteza, compartilhamento do poder e responsabilidade, atuação em prol da cooperação e compreensão e administração dos valores dos integrantes do projeto. Na dimensão conhecimento, os aspectos destacados são: conhecimento dos inputs e outputs do projeto, dos processos a executar e visão holística do projeto. A dimensão ação envolve a aceitação e suporte ao gerenciamento de projetos em todos os níveis da organização, desde a presidência, diretoria, gerência e supervisão até o nível operacional.

A estrutura organizacional é um fator crítico de sucesso para a implementação de uma estratégia organizacional. Portanto, o arranjo organizacional fornece elementos para a inferência sobre os principais direcionadores de uma estratégia organizacional. Patah \& Carvalho (2002) indicam que durante os últimos trinta anos uma revolução vem ocorrendo na introdução e desenvolvimento de novas estruturas organizacionais para fazer frente às necessidades de maior flexibilidade e velocidade no atendimento aos novos requisitos de mercado e mudanças ambientais.

Como alternativa à rigidez da estrutura organizacional funcional ou tradicional, surgiram as estruturas matricial e projetizada. A estrutura matricial, que é uma combinação da funcional e projetizada, ainda pode ser dividida em matricial fraca, equilibrada ou forte. É evidente que a natureza das atividades desempenhadas por uma organização e o tipo de tecnologia de processo adotada, dentro de um continuum de projetos a processos contínuos, influenciam sobremaneira a estrutura organizacional. Porém, deve-se salientar que a adoção de uma estrutura projetizada ou matricial forte pode ser um indício de um maior grau de maturidade organizacional no gerenciamento de projetos.

No tocante à estrutura organizacional voltada especificamente ao gerenciamento de projetos é também muito importante destacar o papel vital do PMO - Project Management Office - Escritório de Projetos. O PMO pode ser definido com a estrutura organizacional estabelecida para apoiar os gerentes e as equipes de projetos na implementação de princípios, práticas, metodologias, ferramentas e técnicas para o gerenciamento de projetos (DAI \& WELLS, 2004). O PMO pode apoiar de forma significativa e contundente a transformação das estratégias da organização em projetos e pla- nos de ação através de um adequado e eficiente gerenciamento de projetos.

Pesquisas, segundo Roolins (2003), apontam para a existência de mais de 50.000 Escritórios de Projetos existentes nos Estados Unidos. Verzuh (1999) argumenta que se uma organização desenvolve projetos de forma esporádica, não há a necessidade de desenvolver de forma sistemática habilidades para as iniciativas de projetos. Todavia, se uma organização dedica grande parte de sua energia à implementação de projetos, uma abordagem não-estruturada e disciplinada para o gerenciamento de projetos conduz a ineficiências que podem ser danosas às organizações. Com um grande número de projetos sendo gerenciados, a necessidade da presença de um PMO torna-se evidente. 
projetos dentro da organização (PATAH \& CARVALHO, 2002a; PATAH \& CARVALHO, 2002b). A mera existência de um escritório de projetos, qualquer que seja a sua modalidade ou tipo, representa um compromisso da organização com a melhoria do gerenciamento de projetos.

\section{OS MODELOS DE MATURIDADE EM GERENCIAMENTO DE PROJETOS}

Modelos de maturidade em gerenciamento de projetos vêm obtendo notoriedade e diversas organizações, entidades normativas, pesquisadores e consultores organizacionais têm desenvolvido normas e modelos de referência que buscam promover o desenvolvimento das competências em gerenciamento de projetos.

Nas áreas de desenvolvimento e engenharia de software, os modelos CMM (Capability Maturity Model) e CMM-I (Capability Maturity Model Integration) têm sido os mais amplamente utilizados. Baseados em conceitos de níveis de maturidade e requisitos estruturais de áreas-chave de processo, esses modelos têm permitido às organizações conduzirem avaliações do nível de maturidade e capabilidade em gestão de projetos de software.

CMM, há cinco níveis de maturidade, assim definidos: nível 1 - Inicial; nível 2 - Gerenciado; nível 3 - Definido, nível 4 - Quantitativamente Gerenciado; e nível 5 Otimizado. Para cada nível de maturidade são definidos conjuntos de requisitos estruturais das áreas-chave de processo. No caso do modelo CMM-I contínuo, o que se obtém é um perfil de maturidade da organização, ou seja, uma avaliação do nível de maturidade de cada uma das áreas-chave de processo. Segundo o modelo CMM-I contínuo há seis níveis de maturidade para cada área de processo, a saber: nível 0 - Incompleto; nível 1 - Realizado; nível 2 - Gerenciado; nível 3 - Definido; nível 4 Quantitativamente Gerenciado e; nível 5 - Otimizado.

No sentido de avaliar a maturidade em gerenciamento de projetos de natureza mais abrangente e genérica do que aqueles associados às áreas de desenvolvimento e engenharia de software, dois modelos conceituais têm sido mais amplamente adotados: o Project Management Maturity Model - PMMM, proposto por Kerzner (2001), e o Organizational Project Management Maturity Model - OPM3, proposto pelo PMI (2003). Utilizando como referência as principais áreas de conhecimento em gerenciamento de projetos e os processos de gerenciamento de projetos abordados pelo $\mathrm{PMBoK}$ Project Management Body of Knowledge - (PMI, 2000), além do conceito de níveis de maturidade do modelo CMM e do modelo CMM-I estagiado, Kerzner (2001) criou o modelo PMMM para o gerenciamento de projetos.

De acordo com Carvalho et al (2003), o PMMM introduz ferramentas de benchmarking para mensurar o progresso de uma organização ao longo de um modelo de maturidade, detalhando cinco ní-

Os modelos CMM e CMM-I foram desenvolvidos pela Carnegie Mellon University em parceria com a SEI Software Engineering Institute. O CMM, cuja versão integral foi publicada em 1993, apresenta cinco níveis de maturidade, sendo cada um deles caracterizado por um conjunto de áreas-chave cuja estruturação é considerada necessária para o projeto e desenvolvimento de softwares (CARVALHO, LAURINDO \& PESSÔA, 2003). Os cinco níveis de maturidade contemplados pelo modelo CMM são: nível 1 - Inicial; nível 2 - Repetitivo; nível 3 Definido; nível 4 - Gerenciado e; nível 5 - Otimizado.

O modelo CMM-I, que teve a sua primeira versão lançada em 2000, possui duas formas de representação: a representação estagiada e a representação contínua. No modelo CMM-I estagiado, de forma análoga ao modelo veis de desenvolvimento para o alcance da plena maturidade em gerenciamento de projetos: nível 1 - Linguagem Comum; nível 2 - Processos Comuns; nível 3 - Metodologia Singular; nível 4 - Benchmarking; e nível 5 Melhoria Contínua. O modelo PMMM, portanto, consegue combinar a estrutura de áreas do PMBoK (2004) com a estrutura de níveis de maturidade do modelo CMM (CMM-I, 2002; CMM-I, 2002b; HUMPHREY, 1989). O modelo proposto pelo PMI (Project Management Institute), denominado de PMBoK (Project Management Body of Knowledge), fornece uma estrutura de referência para a gestão de projetos que abrange nove áreas de conhecimento: (i) integração; (ii) escopo; (iii) tempo; (iv) custo; (v) qualidade; (vi) recursos humanos, (vii) comunicação; (viii) risco; (ix) aquisições. 
Kerzner (2001) propõe um esquema de avaliação particular para cada um dos níveis de maturidade do modelo PMMM. Para o nível 1 - Linguagem Comum -, aplica-se um questionário com 80 questões que cobre todas as principais áreas de conhecimento do PMBoK. Os resultados finais da aplicação do questionário permitem à organização obter um retrato do seu nível de maturidade no tocante à linguagem comum para o gerenciamento de projetos.

Para o nível 2 - Processos Comuns -, do modelo PMMM, Kerzner (2001) identifica um ciclo de vida do gerenciamento de projetos que pode ser desdobrado em cinco fases, a saber: embrionária, aceitação pela alta administração, aceitação pela gerência, crescimento e maturidade. É importante frisar que uma certa simultaneidade entre as fases pode ocorrer. A fase embrionária significa que a organização começa a perceber e reconhecer os benefícios do gerenciamento de projetos - principalmente nos níveis operacionais e de supervisão da organização. As duas fases seguintes, aceitação pela alta administração e pela gerência, são alcançadas quando os conceitos e práticas do gerenciamento de projetos são amplamente aceitos e tornam-se visíveis o suporte e o comprometimento da liderança da organização no patrocínio e condução dos projetos.

Kerzner (2001) enfatiza que a fase de crescimento é a mais crítica, pois marca o início da criação de um processo de gerenciamento de projetos, e alerta que se deve buscar uma padronização nas metodologias para o planejamento, execução e controle dos projetos. A última fase do ciclo de vida, denominada de Maturidade, é difícil de alcançar em função de vários fatores, tais como a resistência da organização em efetuar um rígido controle de prazos e custos com relatórios periódicos dos desvios, o desenvolvimento de uma grade de competência e habilidades em gestão de projetos e a profissionalização da função de gestão de projetos. Um questionário composto de 20 perguntas fornece uma visão do perfil do ciclo de vida do gerenciamento de projetos. A Figura 1 exibe as fases do ciclo de vida que caracterizam o nível 2 de maturidade do modelo PMMM.

No nível 3 do modelo PMMM, Metodologia Singular, Kerzner (2001) propõe um protocolo de questionário para avaliar seis características do chamado hexágono da excelência: processos integrados, cultura, apoio e suporte da liderança, treinamento e educação, "redução da burocracia" no gerenciamento de projetos em função da prática de uma metodologia singular pela organização e o reconhecimento da diferença entre os profissionais de linha e gestão de projetos.

O nível 4 do modelo PMMM, Benchmarking, busca avaliar até que ponto uma organização faz uso do processo e das práticas características do benchmarking para aperfeiçoar o seu gerenciamento de projetos. Para o nível 5 de maturidade do PMMM, denominado de Melhoria Contínua, Kerzner (2001) aborda os processos e práticas adotados pela organização para resguardar, consolidar, aprimorar e disseminar as lições e o aprendizado acumulado com a execução do gerenciamento de projetos na organização.

Figura 1: Project Management Maturity Model - PMMM.

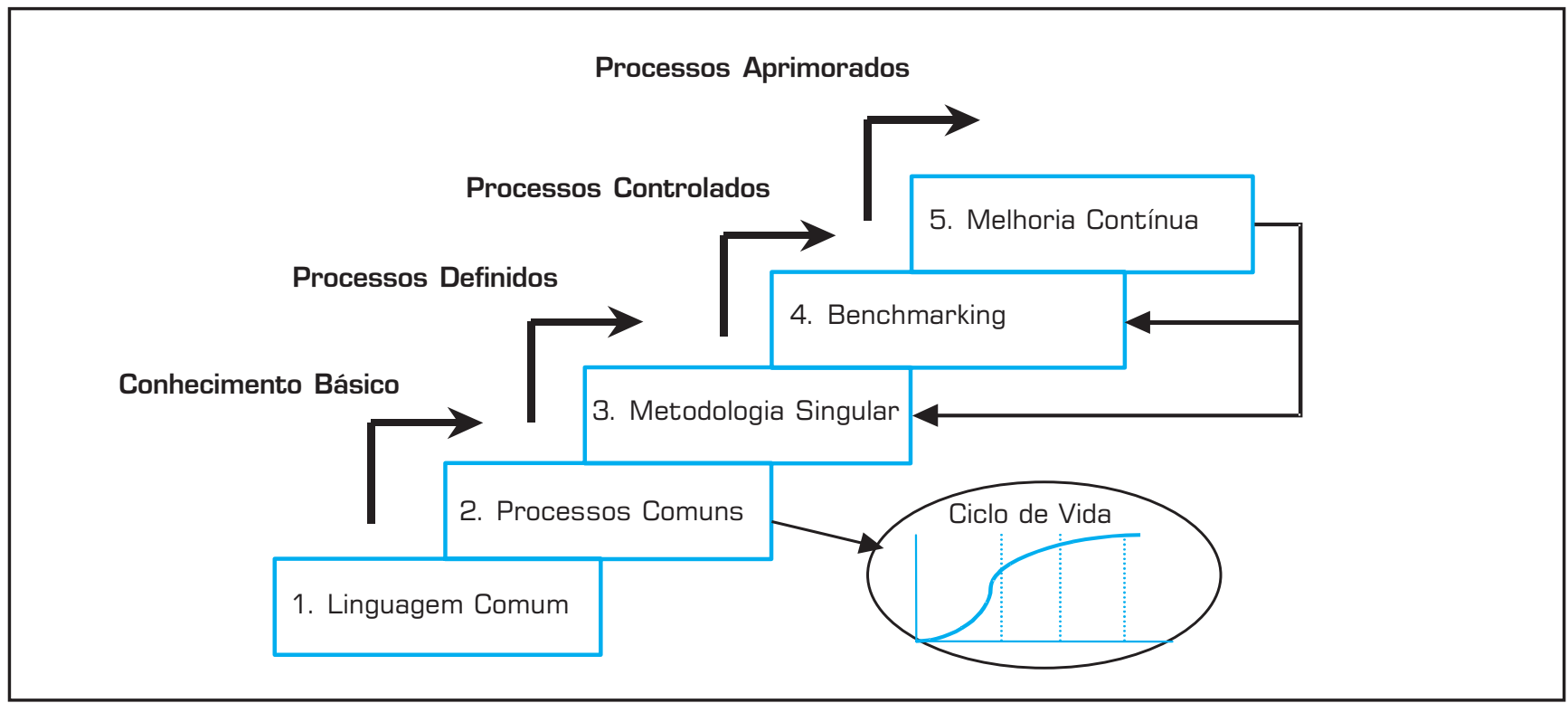

Fonte: Adaptado de KERZNER, 2001. 
O alcance dos níveis 3, 4 e 5 de maturidade do modelo PMMM representa um grande desafio a ser perseguido pelas organizações. Atualmente, as organizações que têm atingido os maiores níveis de maturidade são aquelas que atuam em setores onde a própria natureza das atividades exige uma atenção e dedicação maiores à execução de projetos, tais como, aeroespacial, petrolífero, petroquímico, construção civil, armamento militar e telecomunicações.

Mais recentemente, o Project Management Institute PMI (2003) concluiu a formulação de um modelo de maturidade organizacional denominado de OPM3, Organizational Project Management Maturity Model. O PMI começou a desenvolver o modelo OPM3 em 1998, utilizando uma equipe de voluntários. Em 1999, com o objetivo de estudar os modelos de maturidade existentes, a equipe aplicou um questionário para mais de 30.000 profissionais da área de gerenciamento de projetos (SCHLICHTER et al, 2003). De acordo com o PMI (2003), o significado de OPM3, ou modelo de maturidade para o gerenciamento de projeto, pode ser definido da seguinte forma: Organizational, implica em uma ampliação do escopo, a área de domínio abordada pelo modelo, ultrapassando o contexto específico do projeto em si mesmo, objeto principal de foco do PMBoK. O uso da palavra Maturity implica que as capacidades de gerenciamento devem evoluir ao longo do tempo com o objetivo de produzir de forma sistemática e contínua resultados de sucesso no gerenciamento de projetos. Maturity pode ser entendido como desenvolvimento total ou em perfeitas condições. Maturity também demonstra uma compreensão e domínio ou fornece visibilidade de como o sucesso ocorre e quais as abordagens para a correção ou prevenção de problemas comuns.

Os pontos a seguir destacam e reforçam o contexto estratégico do OPM3 (PMI, 2003):

- O gerenciamento de projetos em uma organização não é simplesmente uma metodologia para gerenciar projetos; tal tema é endereçado pelo PMBoK;

- Seu domínio estratégico inclui outras perspectivas e sistemas para assegurar a entrega de múltiplos projetos dentro da organização;

- O modelo deve proporcionar a adequada vinculação das atividades de alinhamento das prioridades estratégicas e da infra-estrutura que prepara o ambiente para a gestão de projetos;

- O modelo deve fortalecer o vínculo entre a estratégia organizacional e a execução, contribuindo para aumentar a taxa de sucesso na realização dos projetos;

- O modelo deve incluir capacidades que diferenciam as organizações, que são capazes de traduzir a estratégia organizacional e executá-la com resultados de projetos bem-sucedidos;

- Rotinas organizacionais podem tornar os projetos mais alinhados à estratégia organizacional, incluindo a priorização de projetos, o gerenciamento do portfólio de projetos e do ambiente organizacional mais apropriado à gestão de projetos.

Figura 2: Modelo de Maturidade OPM3.

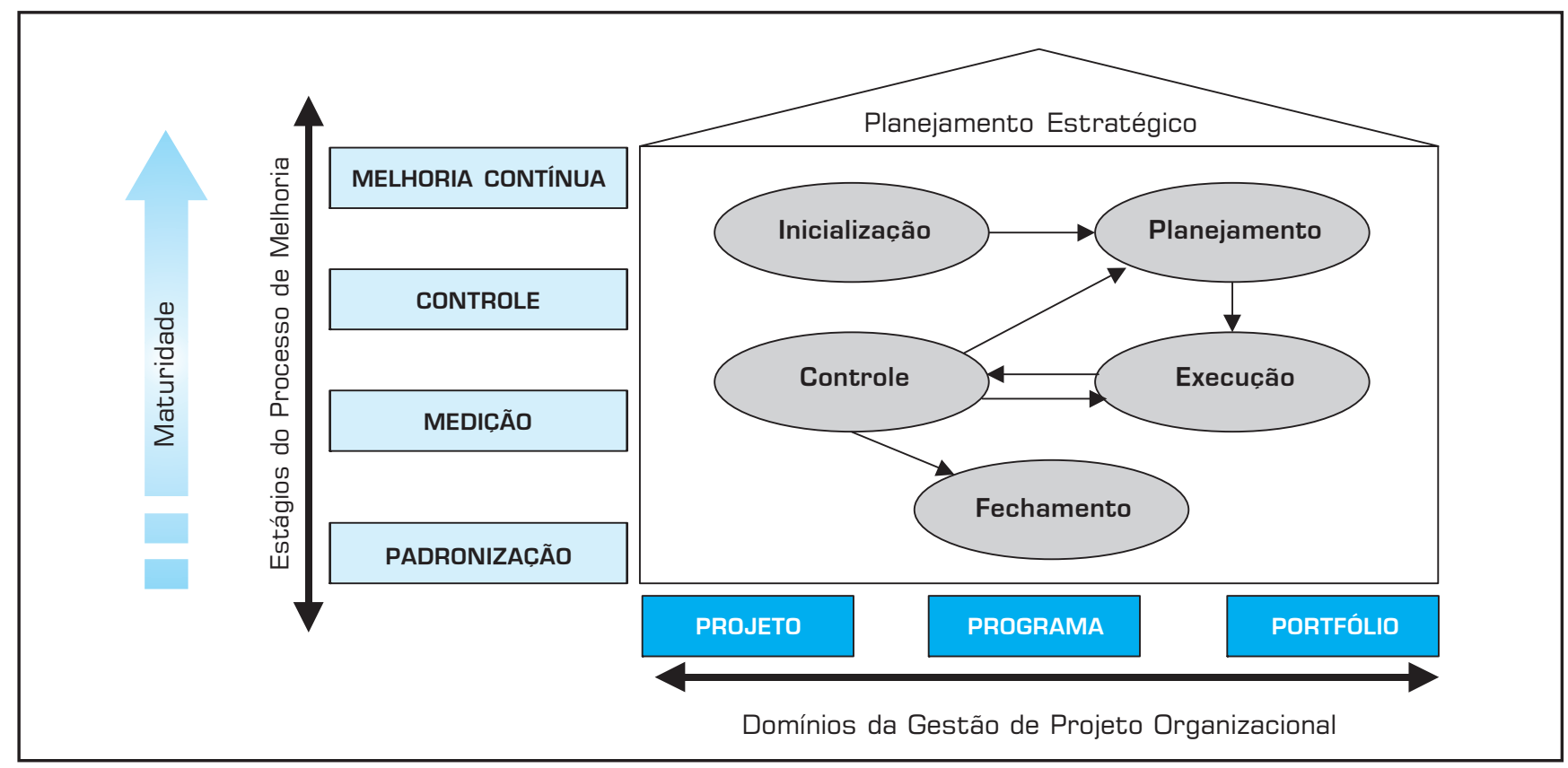

Fonte: Adaptado de PMI, 2003. 
O modelo OPM3 parte do conceito de ciclo de vida do projeto, já existente no $\mathrm{PMBoK}$, enfocando os principais processos envolvidos no gerenciamento de projetos: inicialização, planejamento, execução, controle e fechamento. Além disso, o modelo identifica quatro estágios de melhoria: padronização, mensuração, controle e melhoria contínua. Finalmente, o modelo considera três domínios relevantes: projeto, programa e portfólio. A Figura 2 exibe a estrutura do modelo OPM3 (PMI, 2003).

\section{PROJETO DE PESQUISA}

Com o objetivo de estudar, compreender e avaliar o papel e a influência de uma metodologia singular de gestão de projetos no nível de maturidade em gerenciamento de projetos de uma organização, adotou-se a metodologia do estudo de caso, conforme indicado por Yin (1991). O estudo de caso foi desenvolvido na subsidiária brasileira de uma multinacional do segmento de iluminação.

A análise do estudo de caso, conforme indicado na metodologia proposta para o desenvolvimento do artigo, abrange duas frentes de trabalho: (1) uma pesquisa documental, fonte secundária de dados, através da apresentação e descrição dos aspectos principais da metodologia singular de gerenciamento de projetos adotada e executada pela empresa, a qual recebe a denominação de MEDIC; (2) uma pesquisa de campo, fonte primária de dados, através da aplicação de um questionário baseado no modelo Project Management Maturity Model (PMMM), para avaliar a percepção da gerência das principais áreas da empresa com respeito à maturidade organizacional no gerenciamento de projetos.

Para a aplicação de um modelo de maturidade em gestão de projetos para o estudo de caso do presente artigo, optou-se pela seleção do modelo de maturidade PMMM. Essa escolha justifica-se pelo fato do PMMM possuir um escopo e abrangência adequados para a avaliação da maturidade em gestão de projetos de natureza mais genérica do que projetos voltados à área de tecnologia da informação, bem como proporciona um esquema de avaliação disciplinado, organizado e de fácil aplicação e interpretação. Mais especificamente, o instrumento selecionado para a pesquisa de campo do estudo de caso foi o protocolo de questionário proposto pelo modelo PMMM para avaliar as fases do ciclo de vida do nível 2 de maturidade - Processos Comuns. Esse instrumento é baseado em um conjunto de 20 questões que devem ser respondidas adotando-se uma escala de avaliação de percepção que varia de -3 (discordo totalmente) a +3 (concordo totalmente).

\section{Breve Histórico da Empresa}

A empresa selecionada para o estudo de caso foi a subsidiária brasileira de uma multinacional do segmento de iluminação, categoria de produto lâmpadas, que atua nas quatro principais regiões do mundo: Europa, Ásia, América do Norte e América Latina. Para o presente estudo de caso, selecionou-se o escritório regional da América Latina (LatAm Office), que possui responsabilidade pelo direcionamento e gerenciamento de quatro clusters: Brasil, México, Cluster Cone Sul e Cluster Andino. No ano de 2003, a divisão Lâmpadas América Latina possuía 1.160 funcionários e atingiu um faturamento de 161.570 milhões de dólares.

\section{devem evoluir ao longo do tempo com o objetivo de produzir de forma sistemática e contínua resultados de sucesso no gerenciamento de projetos.}

\section{Pesquisa Documental: \\ A Metodologia Singular MEDIC}

A metodologia MEDIC foi criada no ano de 2000 pelo grupo corporativo de qualidade da empresa, sediado na Europa. A partir de um processo de benchmarking das metodologias em gestão de projetos adotadas por organizações reconhecidas como "best-in-class", instituiu-se o MEDIC como a metodologia singular da empresa para a gestão dos processos de melhoria e mudança organizacional. Os gerentes de qualidade regionais foram encarregados de efetuar o desdobramento dessa metodologia em suas regiões. No caso particular da região América Latina, a estrutura organizacional é tipicamente funcional e não há nenhum tipo de arranjo organizacional em termos de escritório de projetos. A própria área de qualidade da América Latina foi incumbida de ser a guardiã dos conceitos, métodos, padrões e procedimentos da metodologia MEDIC na região.

A metodologia MEDIC abrange as seguintes fases para o gerenciamento de projetos: M (Map \& Measure), E (Evaluate \& Explore), D (Define \& Describe), I (Implement \& Improve) e C (Control \& Conform). A 
implementação efetiva da metodologia MEDIC exige o cumprimento das seguintes etapas: identificação das oportunidades de melhoria e necessidades de mudança organizacional, identificação e seleção do sponsor do projeto, treinamento do sponsor na metodologia MEDIC no centro de treinamento na Europa, elaboração e aprovação do Project Charter, aplicação faseada da metodologia MEDIC com a geração de um relatóriopadrão ao final de cada fase da metodologia (MEDIC Fact Reports), consolidação da execução e dos resultados do projeto em um Evidence Book e avaliação e validação do Evidence Book pelo Comitê Corporativo de Qualidade. Por orientação da qualidade corporativa, a metodologia MEDIC foi inicialmente direcionada para projetos de maior impacto ("breakthroughs") tendo como principais agentes de mudança e/ou sponsors dos projetos os black-belts.

\section{Pesquisa de Campo: Avaliação do Nível de Maturidade - Modelo PMMM}

Com o intuito de averiguar a maturidade organizacional em gerenciamento de projetos, segundo a visão e percepção das principais áreas de negócio da empresa, foi conduzida uma pesquisa de campo, fonte de dados primários, através da aplicação do protocolo de questionário proposto por Kerzner (2001) para a avaliação do nível 2 de maturidade do modelo PMMM, Processos Comuns, o qual permite obter um posicionamento da empresa em relação às fases do ciclo de vida do gerenciamento de projetos. A estrutura do questionário e a forma de apuração da pontuação para cada uma das fases do ciclo de vida estão no Anexo 1.

A escolha do questionário estruturado do nível 2 de maturidade do modelo PMMM justifica-se pelo fato desse nível de maturidade ser uma espécie de "divisor de águas" no tocante à maturidade organizacional no gerenciamento de projetos. Uma elevada pontuação na seqüência das fases que compõem o ciclo de vida embrionária, aceitação pela alta direção, aceitação pela gerência média e operacional, crescimento e maturidade -, pode indicar que a empresa está apta e em condições de avançar para o nível 3 de maturidade do modelo PMMM, denominado de Metodologia Singular. Por outro lado, uma baixa pontuação nas fases mais avançadas do ciclo de vida do gerenciamento de projetos - aceitação pela gerência média e operacional, crescimento e maturidade - pode indicar que, na realidade, a empresa encontra-se no nível de maturidade 1 do modelo PMMM, denominado de Linguagem Comum. Para a aplicação do questionário foram selecionadas dentro da empresa as áreas de negócio que, em função da natureza de suas atividades, estão diante de desafios e processos de melhoria e mudança que exigem o desenvolvimento de projetos. As áreas selecionadas foram: Tecnologia da Informação (TI), Logística \& Cadeia de Suprimentos, Business to Business (B2B), Qualidade e Marketing.

Os principais resultados da pesquisa de campo são exibidos a seguir.

A Figura 3 apresenta uma caracterização geral do perfil dos projetos em termos de número médio de pessoas envolvidas nas equipes de projetos, prazo médio para execução dos projetos (em meses) e o investimento médio (em milhares de reais) para a realização dos projetos. Em geral, os projetos de Tecnologia da Informação e Logística envolvem um maior número de colaboradores, os projetos de B2B e Qualidade são os de maior prazo e, na média, os investimentos dos projetos das várias áreas de negócio possuem uma mesma faixa de valor.

A Figura 4 retrata o perfil da pontuação geral das várias áreas de negócio segundo as fases do ciclo de vida no gerenciamento de projetos: embrionária, aceitação pela alta direção, aceitação pela gerência, crescimento e maturidade. As áreas de Qualidade, B2B e Tecnologia da Informação, pela natureza de suas atividades e pelo expertise pessoal de seus colaboradores, são aquelas que apresentam as maiores pontuações. Logística tem uma boa pontuação apenas na fase embrionária, ao passo que Marketing ainda demostra baixo grau de maturidade.

Segundo Kerzner (2001) uma pontuação igual ou superior a +6 indica que a empresa foi capaz de cumprir com êxito uma determinada fase do ciclo de vida.

Nos últimos 3 anos, o total de projetos realizados em cada área foi de: Tecnologia da Informação -7 projetos, Logística \& Cadeia de Suprimentos - 4 projetos, B2B - 5 projetos, Qualidade -4 projetos e Marketing -4 projetos. Nas áreas de Logística e Marketing, a metodologia singular MEDIC foi aplicada em 20\% dos projetos, nas áreas de Qualidade e Tecnologia da Informação o MEDIC foi adotado em $50 \%$ dos projetos e na área de B2B em $75 \%$ dos projetos realizados. A figura 5 resume as informações sobre a aplicação do MEDIC.

\section{CONCLUSÕES}

O objetivo principal do presente artigo é o de discutir efetivamente se o fato de uma organização possuir uma metodologia singular de gerenciamento de projetos, já definida e implementada, é condição suficiente para afirmar que uma organização possui maturidade no gerenciamento de projetos. Com o intuito de analisar e debater essa questão, apresentou-se o conceito, a estrutura e os aspectos principais da metodologia singular MEDIC, formulada e implementada pela empresa objeto do estu- 
Figura 3: Caracterização do Perfil dos Projetos por Área de Negócio.

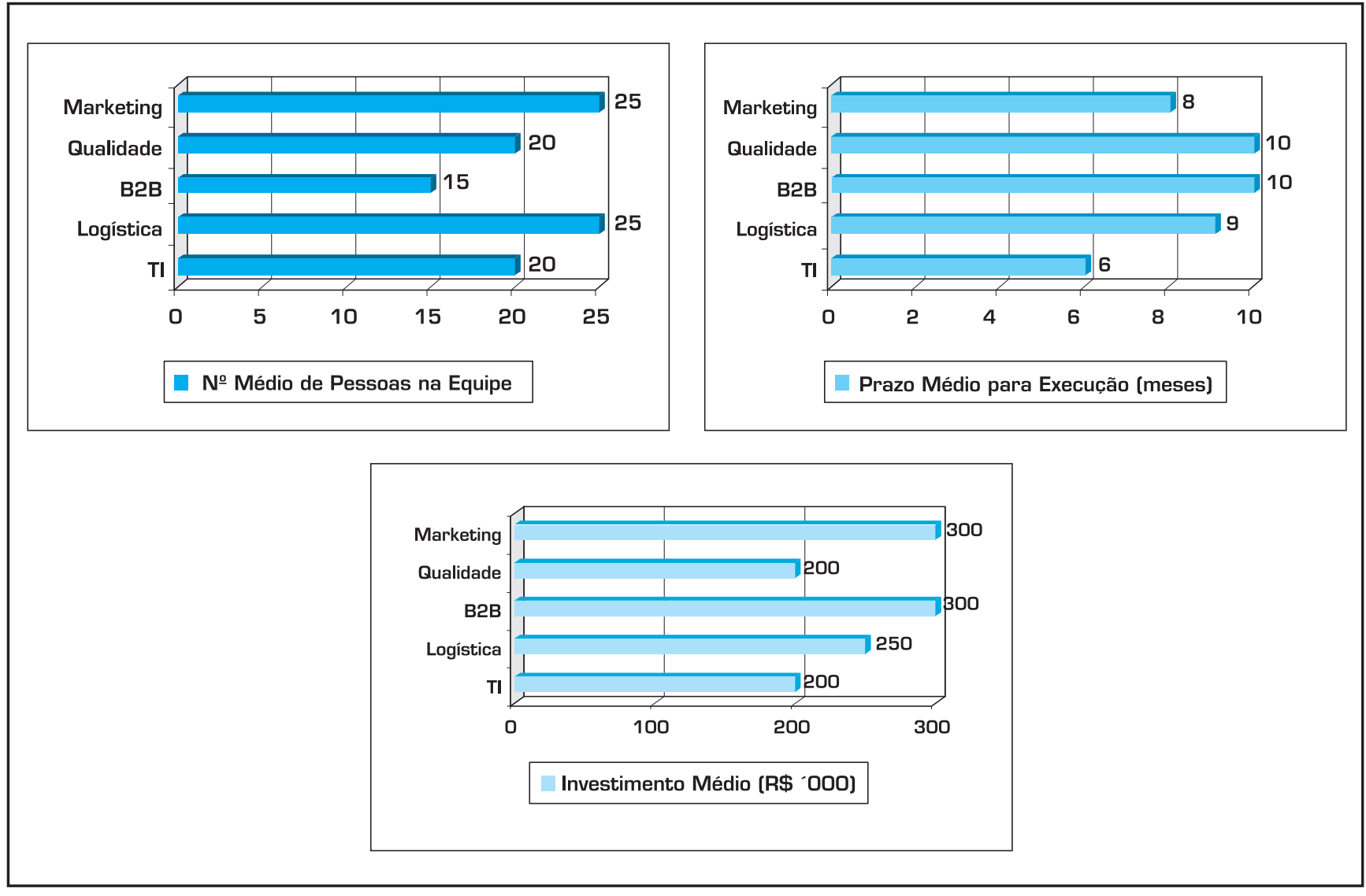

Figura 4: Pontuação nas Fases do Ciclo de Vida no Gerenciamento de Projetos.
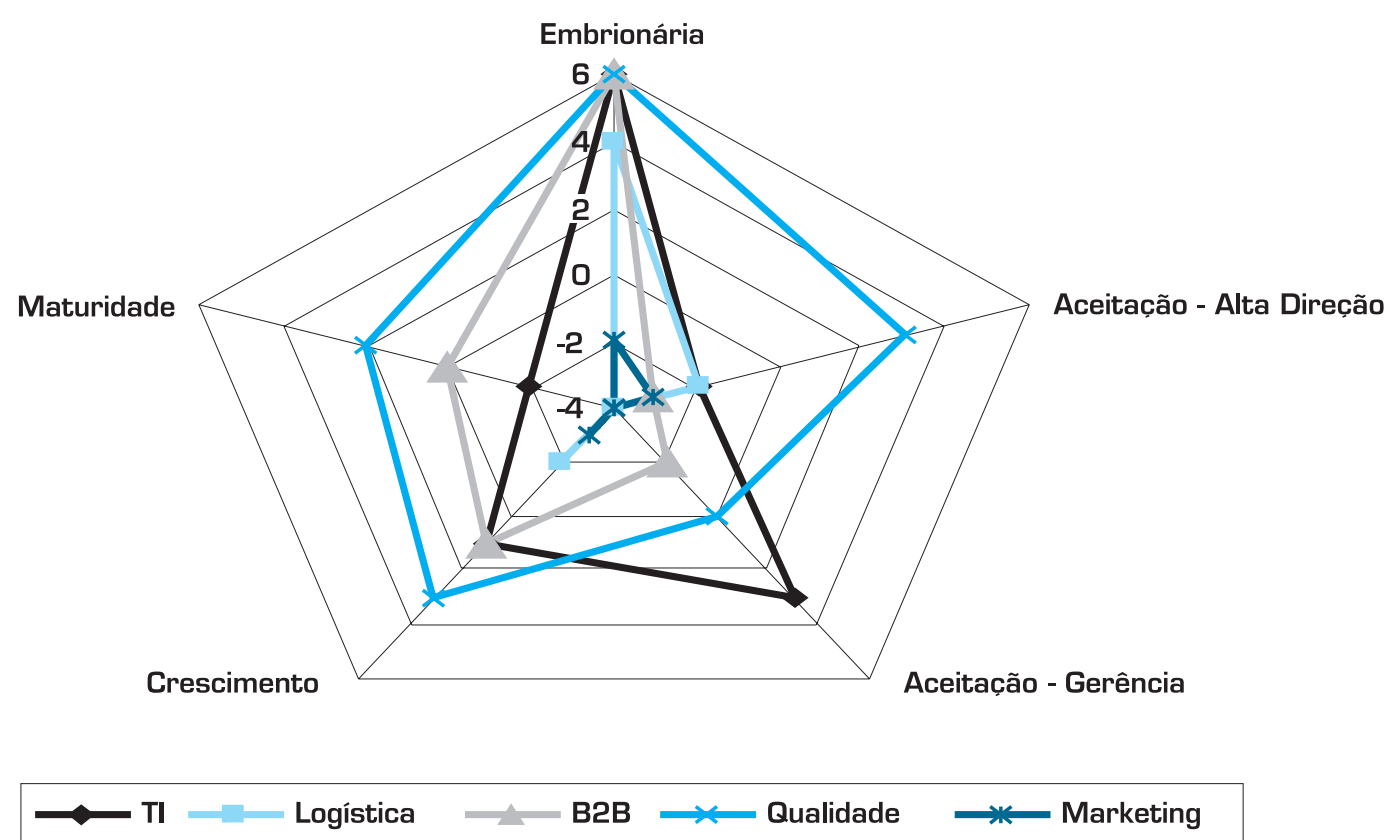
do de caso, além dos resultados da aplicação do questionário sobre maturidade na gestão de projetos para retratar a avaliação e percepção das principais áreas de negócio da empresa no tocante ao contexto organizacional e ao grau de maturidade no gerenciamento de projetos.

A pesquisa documental realizada comprova a existência da criação e implementação de uma metodologia singular para a gestão dos projetos de melhoria e mudança da empresa. Há todo um conjunto de regras e procedimentos que asseguram o cumprimento e o registro de evidências de cada uma das fases da metodologia MEDIC. A validação dos resultados do projeto e o efetivo reconhecimento das realizações passam por um processo de avaliação e validação bastante rigoroso assegurando a sua credibilidade e confiabilidade. Todavia, como se assinalou, essa metodologia singular ainda é restrita para uma parcela privilegiada da empresa, os "black-belts", não se configurando um efetivo desdobramento dessa metodologia por toda a empresa. Os resultados apurados na pesquisa de campo quanto à avaliação e percepção do grau de maturidade organizacional em gestão de projetos são também bastante reveladores: nota-se que apenas na fase embrionária do ciclo de vida do gerenciamento de projetos a empresa recebe uma pontuação positiva de maior destaque. Nas demais fases, a baixa pontuação obtida sinaliza que ainda não há maturidade organizacional suficiente. Vale ressaltar que as áreas de Tecnologia da Informação e B2B obtiveram maior pontuação em outras fases do ciclo de vida pela particularidade de fazerem uso de recursos black-belts para a condução de seus principais projetos. A pontuação da área da Qualidade é influenciada pelo fato de ela ser a guardiã do MEDIC.

Os resultados da pesquisa de campo também revelaram que, na percepção e avaliação das principais áreas de negócio, a metodologia MEDIC apresenta os seguintes pontos fortes: metodologia bem estruturada e com uma lógica clara e objetiva de progresso do projeto, fácil entendimento, ênfase na medição e follow-up, promoção do gerenciamento baseado em fatos e dados, apoio para as equipes multifuncionais e abordagem e tratamento do fator humano na gestão de projetos. Por outro lado, foram apontadas as seguintes áreas de melhoria na metodologia MEDIC: gerenciamento de custos e recursos alocados ao projeto, gerenciamento do risco do projeto e desdobramento da metodologia pela empresa.

Kerzner (2001) destaca que para uma empresa alcançar o nível de maturidade 3 no modelo PMMM, denominado de Metodologia Singular, uma empresa deve apresentar, além de uma metodologia singular definida e implementada para a gestão de projetos, também os seguintes elementos que, em seu todo, compõem o hexágono da excelência: cultura organizacional apropriada para a gestão de projetos, aceitação e suporte dos vários níveis hierárquicos da empresa, uma otimização no gerenciamento dos documentos e registros dos projetos, um processo de educação e treinamento estabelecido para a gestão de projetos e uma excelência comportamental no reconhecimento e apoio para a gestão de projetos.

A existência de uma metodologia singular de gestão de projetos, definida e implementada, não é, por si só, um elemento suficiente para atestar o grau de maturidade organizacional na gestão de projetos. Um conjunto de elementos fundamentais que gravitam em torno da existência de uma metodologia singular, incluindo-se aí os elementos do hexágono da excelência enfatizados por Kerzner (2001), uma estrutura organizacional matricial ou projetizada que suporte e promova a gestão de projetos e uma organização apropriada para a gestão de proje-

Figura 5: Número de Projetos Desenvolvidos vs. \% de Aplicação da Metodologia MEDIC.

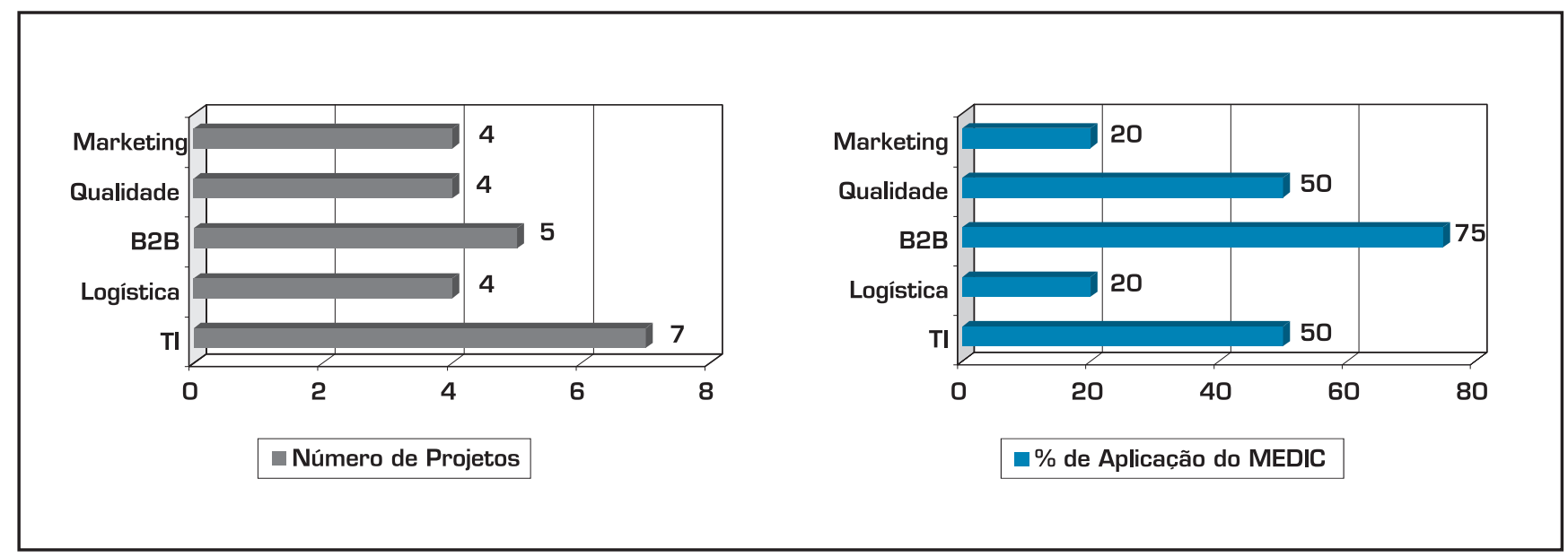


tos, como por exemplo um centro de excelência em gestão de projetos, também devem estar presentes e ativos para corroborar a efetiva maturidade organizacional em gestão de projetos. A empresa analisada no estudo de caso encontra-se na trajetória apropriada na busca da sua maturidade em gestão de projetos. A existência e prática de uma metodologia singular com vários pontos positivos destacados é um claro sinal dessa jornada, porém há ainda uma série de elementos estruturais, organizacionais e culturais que precisam ser adequadamente abordados para que a empresa possa atingir uma efetiva maturidade organizacional na gestão de projetos.

\section{Artigo recebido em 11/07/2005 Aprovado para publicação em 25/10/2005}

\section{- Referências Bibliográficas}

ANDERSEN, E.S.; JESSEN, S. A. Project maturity in organization. Internationa Journal of Project Management, $\mathrm{N}$. 21 , p. 457-461, 2002.

CARVALHO, M.M; LAURINDO, F.J.B.; PESSÔA, M.S.P. Information Technology Project Management to achieve efficiency in Brazilian Companies. In: KAMEL, Sherif. (Org.). Managing Globally with Information Technology. Hershey, p. 260-271, 2003.

CMM-I (2002a). Capability Maturity Model Integration - version 1.1 - for System Engineering and Software Engineering - continuous representation CMU/SEI/SW, V1.1 CMU/SEI - 2002 - TR01 downloaded from www.sei.cmu.edu (02-02-2002).

CMM-I (2002b). Capability Maturity Model Integration - version 1.1 for System Engineering and Software Engineering - staged representation CMU/SEI/SW, V1.1 CMU/SEI - 2002 - TR02 downloaded from www.sei.cmu.edu (02-02-2002).
COOKE-DAVIES, T.J.; ARZYMANOW, A. The maturity of project management in different industries: An investigation into variations between project management models. International Journal of Project Management, n. 21, p. 471$478,2003$.

DAI, C.X.; WELLS, W.G. An exploration of project management office features and their relationship to project performance. International Journal of Project Management, n. 22, p. 523-532, 2004.

DINSMORE, P.C. (1998) Winning Business with Enterprise Project Management. New York: AMACOM.

GRAY, R.J. Organisational Climate and project success. International Journal of Project Management, n. 19, p. 103109, 2001.

HUMPHREY, W.S. (1989) Managing the software process. Reading, Addison-Wesley (SEI series in software engineering)
KERZNER, H. Strategic Planning for Project Management using a project management Maturity Model. Nova York: John Wiley \& Sons, 2001.

PATAH, L.A.; CARVALHO, M.M. Estruturas de gerenciamento de projetos e competências em equipes de projetos. In: ENEGEP XXII, 2002, Curitiba. Porto Alegre: ABEPRO, p. $1-8$

PATAH, L.A.; CARVALHO, M.M. O processo de escolha de estruturas de gerenciamento de projetos em empresas. In: Simpósio de Engenharia de Produção, 9, 2002, Bauru. SIMPEP IX. Bauru: UNESP, p. 1-11.

PMI, Project Management Institute (2004). A Guide to the Project Management Body of Knowledge (PMBoK). 3rd edition. Project Management Institute Inc.

PMI, Project Management Institute (2003). Organizational Project Management Maturity Model (OPM3). Project Management Institute Inc.
RABECHINI JR, R.; CARVALHO, M.M 1999. Concepção de um programa de gerência de projetos em instituição de pesquisa. Revista Valenciana Dèstudis Autonòmics. Espanha: Valência,

ROOLINS, S. the value of a PMO, 2003. download http://www $\mathrm{p} \mathrm{mo} \mathrm{u} \mathrm{s} \mathrm{a.c} \mathrm{o} \mathrm{m} \mathrm{/} \mathrm{c} \mathrm{f} \mathrm{m} \mathrm{/}$ ligs_hm_pg_content_page.cfm?var $=411$ em $09 / 2003$

SCHLICHTER, J.; FRIEDRICH, R.; HAECK, B. The history of OPM3. In PMI's Global Congress Europe 2003 Den Haaz - Netherlands. Download http://www.pmforum.org/library/ papers/thehistoryofopm3.htm

VERZUH, E. The fast forward MBA in Project Management. New York: John Wiley \& Sons: 1999.

White, D.; FORTUNE, J. Current practice in project management - an empirical study. International Journa of Project Management, n. 20, p. 1-11, 2002.

YIN, R.K. Case Study Research: Design and Methods. Newbury Park, Rev. ed. Sage Publications, 1991 .

- Sobre os autores

\section{Ruy Bouer}

Doutorando do Depto. de Eng. Produção - Escola Politécnica da USP

Endereço: Av. Prof. Almeida Prado, 128 - Tr.2 Biênio - 2º andar - 05508-900 São Paulo - SP - Brasil

Telefone: (11) 3091-5363 - Fax: 3091-5399

E-mail: ruybouer@uol.com.br

\section{Marly Monteiro de Carvalho}

Profa. Dra. do Depto. de Eng. Produção - Escola Politécnica da USP

Endereço: Av. Prof. Almeida Prado, 128 - Tr. 2 Biênio - 2º andar - 05508-900 - São Paulo - SP - Brasil

Telefone: (11) 3091-5363 - Fax: 3091-5399

E-mail: marlymc@usp.br 


\section{ANEXO 1 - QUESTIONÁRIO DE AVALIAÇÃO:}

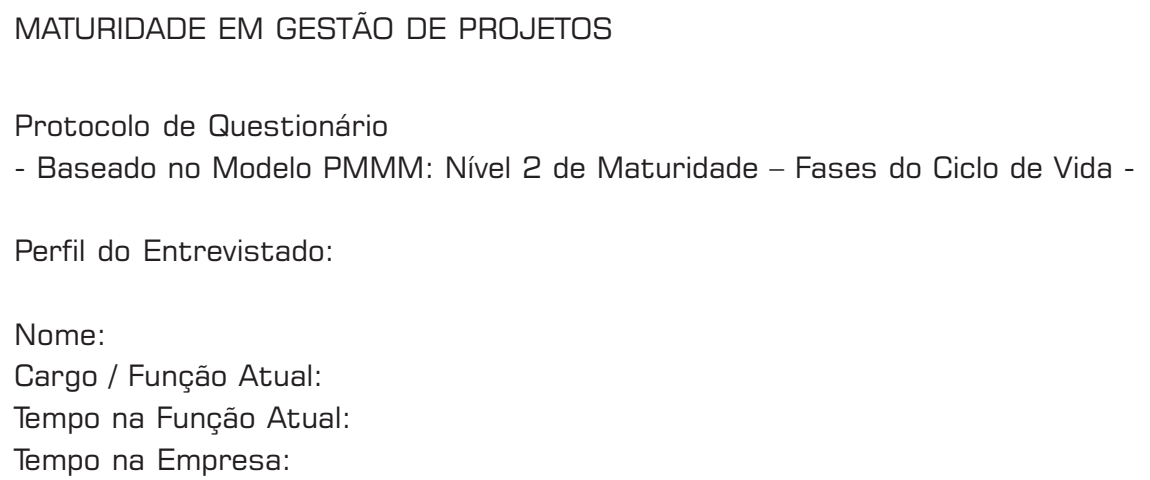

Nome:

Cargo / Função Atual:

Tempo na Função Atual:

Tempo na Empresa:

\section{SESSÃo I - AVALIAÇÃo DA MATURIDADE EM GESTÃo DE PROJETOS}

Nas páginas você encontrará 20 questões que o ajudarão a definir o grau de maturidade que, segundo a sua avaliação e percepção, sua empresa atingiu. Abaixo de cada questão, você deverá assinalar o número correspondente a sua avaliação / percepção, segundo a legenda exibida a seguir:

(-3):Discordo Totalmente

(-2):Discordo

(-1):Discordo Parcialmente

( 0 ):Sem opinião

(+1):Concordo Parcialmente

$(+2):$ Concordo

$(+3)$ :Concordo Totalmente

A pontuação para cada uma das questões varia de $(-3)$ a $[+3]$ e será posteriormente utilizada para a avaliação dos resultados. Dessa forma, solicita-se que o entrevistado marque com um "X" a resposta para cada uma das 20 questões apresentadas a seguir. Seja, por favor, o mais honesto possível nas suas respostas. Marque a resposta que você considera correta, não aquela que você desejaria ou imaginaria que fosse a mais adequada.

Questão 1:

Minha empresa reconhece a necessidade da gestão de projetos. Esta necessidade é reconhecida em todos os níveis da gerência, inclusive pela gerência sênior.
Discordo Totalmente
$(-3) \quad[-2)$
$(-1)$
(O)
$[+1] \quad[+2]$
$(+3)$
Concordo Totalmente

Questão 2:

Minha empresa tem um sistema para gerenciar tanto o custo quanto o cronograma dos projetos. 0 sistema requer números de encargos financeiros e códigos de conta contábil. O sistema informa variações em relação aos objetivos planejados.

\section{Discordo Totalmente $\quad(-3) \quad(-2) \quad(-1) \quad(0) \quad(+1) \quad(+2) \quad(+3) \quad$ Concordo Totalmente}

Questão 3:

Minha empresa tem reconhecido as vantagens possíveis de serem alcançadas através da implementação da gestão de projetos. Estes benefícios são reconhecidos em todos os níveis gerenciais, incluindo a gerência sênior.
Discordo Totalmente
$(-3) \quad(-2)$
$[-1]$
(O)
$(+1)$
$(+2)$
$(+3)$
Concordo Totalmente 
Questão 4:

Minha empresa ou departamento tem uma metodologia facilmente identificável de gestão de projetos que utiliza o conceito de fases ou ciclo de vida de um projeto.
Discordo Totalmente
(-3)
$(-2)$
$(-1)$
(O)
$[+1]$
$(+2)$
$(+3)$
Concordo Totalmente

Questão 5:

Nossos executivos apóiam ostensivamente a gestão de projetos por meio de palestras, curso, artigos e inclusive pela presença ocasional em reuniões e relatórios da equipe de projetos.

\section{Discordo Totalmente $\quad[-3] \quad[-2] \quad[-1] \quad[0] \quad[+1] \quad[+2] \quad[+3] \quad$ Concordo Totalmente}

Questão 6:

Minha empresa tem o compromisso com o planejamento antecipado visando à qualidade. Tentamos fazer sempre o melhor possível em matéria de planejamento.
Discordo Totalmente
$(-3)$
$[-2]$
$(-1)$
(O)
$(+1)$
$(+2)$
$(+3)$
Concordo Totalmente

Questão 7:

Nossos gerentes de área de níveis médio e inicial apóiam por completo e de forma ostensiva o processo de gestão de projetos.
Discordo Totalmente
$[-3]$
$(-5)$
$[-1]$
(O)
$[+1]$
$(+2)$
$(+3)$
Concordo Totalmente

Questão 8:

Minha empresa faz o possível para minimizar os desvios de escopo (por exemplo, mudança de escopo ou redefinição da extensão do escopol em nossos projetos.
Discordo Totalmente
$(-3)$
$(-2)$
$[-1]$
(O)
$(+1) \quad(+2) \quad(+3)$
Concordo Totalmente

Questão 9:

Nossos gerentes de área estão comprometidos não apenas com a gestão dos projetos, mas também com o cumprimento dos prazos estabelecidos para a conclusão dos objetivos.
Discordo Totalmente
$(-3)$
$(-2)$
$(-1)$
(0) $[+1]$
$(+2)$
$(+3)$
Concordo Totalmente

Questão 10:

Os executivos em minha empresa têm bom conhecimento dos princípios de gestão de projetos.
Discordo Totalmente
[-3]
$(-2)$
$[-1]$
(O)
$(+1) \quad(+2) \quad(+3)$
Concordo Totalmente

Questão 11:

Minha empresa selecionou um ou mais softwares para serem utilizados como sistema de controle dos projetos.
Discordo Totalmente
$[-3)$
$(-2)$
$[-1]$
(O)
$(+1) \quad(+2) \quad[+3)$
Concordo Totalmente

Questão 12:

Nossos gerentes de área de níveis médio e inicial foram treinados e instruídos em gestão de projetos.
Discordo Totalmente
(-3)
$(-2)$
$[-1]$
(O)
$(+1)$
$(+2)$
$(+3)$
Concordo Totalmente 
Questão 13:

Nossos executivos compreendem o conceito de responsabilidade e atuam como patrocinadores ("sponsors") em determinados projetos.
Discordo Totalmente
$[-3] \quad[-2]$
$[-1)$
(O)
$(+1) \quad[+2]$
$(+3)$
Concordo Totalmente

Questão 14:

Nossos executivos reconheceram ou identificaram as aplicações da gestão de projetos nas várias divisões [demais unidades de Lighting] do nosso empreendimento.

\section{Discordo Totalmente $\quad[-3) \quad[-2) \quad[-1] \quad(0) \quad[+1] \quad(+2) \quad(+3) \quad$ Concordo Totalmente}

Questão 15:

Minha empresa conseguiu integrar com sucesso o controle de custo e cronogramas tanto para a gestão de projetos quanto para relatórios de follow-up.

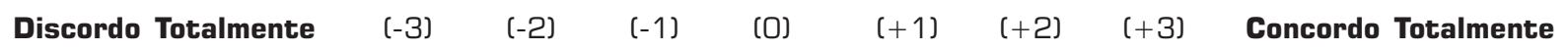

Questão 16:

Minha empresa desenvolveu um currículo de gestão de projetos (por exemplo, mais do que um ou dois cursos de capacitação) para o aperfeiçoamento das qualificações de nossos colaboradores em gestão de projetos.
Discordo Totalmente
$(-3)-(-2)$
$[-1]$
(O)
$(+1) \quad(+2) \quad(+3)$
Concordo Totalmente

Questão 17:

Nossos executivos reconheceram o que precisa ser feito a fim de ser alcançada a maturidade em gestão de projetos.

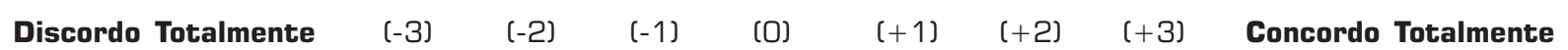

Questão 18:

Minha empresa considera e trata a gestão de projetos como profissão, e não apenas como tarefa de tempo parcial ou, quando requerido, tempo integral.
Discordo Totalmente
$[-3]$
$(-2)$
$[-1]$
(O)
$(+1)$
$(+2)$
$(+3)$
Concordo Totalmente

Questão 19:

Nossos gerentes de área e nível médio estão dispostos a liberar seus funcionários para o treinamento em gestão de projetos.

\section{Discordo Totalmente $\quad[-3] \quad[-2] \quad[-1] \quad[0] \quad[+1] \quad[+2] \quad[+3] \quad$ Concordo Totalmente}

Questão 20:

Nossos executivos têm demonstrado disposição para mudança na maneira tradicional de conduzir negócios para chegar à maturidade em gestão de projetos.

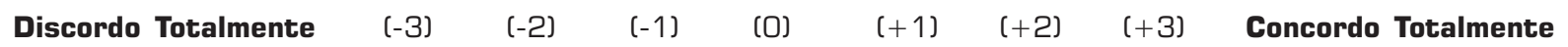




\section{AVALIAÇÃO DA MATURIDADE EM GESTÃO DE PROJETOS}

\section{FORMULÁRIO PARA APURAÇÃO DA PONTUAÇÃO POR FASE DO CICLO DE VIDA}

Para cada uma das questões (questões de número 1 até 20) da sessão I você assinalou uma resposta com seu respectivo valor de pontuação, variando de (-3) até $(+3)$. Nos espaços apropriados, indicados nas tabelas a seguir, favor transcrever o valor assinalado ao lado do número corresponde às questões respondidas.

\section{Fase: Embrionária}

Número da Questão

$$
\begin{gathered}
\text { \# } 1 \\
\text { \# } 3 \\
\text { \# } 14 \\
\text { \# } 17 \\
\text { Total }
\end{gathered}
$$

Fase: Aceitação - Alta Direção

Número da Questão

\# 5

\# 10

\# 13

\# 20

Total

\section{Fase: Aceitação - Gerência}

Número da Questão

$$
\begin{gathered}
\text { \# } 7 \\
\text { \# } 9 \\
\text { \# } 12 \\
\text { \# } 19 \\
\text { Total }
\end{gathered}
$$

\section{Fase: Crescimento}

Número da Questão

$$
\begin{gathered}
\text { \# } 4 \\
\text { \# } 6 \\
\text { \# } 8 \\
\text { \# } 11
\end{gathered}
$$

Total

\section{Fase: Maturidade}

Número da Questão

$$
\begin{gathered}
\text { \# } 2 \\
\text { \# } 15 \\
\text { \# } 16 \\
\text { \# } 18 \\
\text { Total }
\end{gathered}
$$

Valor da Pontuação

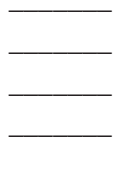

Valor da Pontuação

Valor da Pontuação

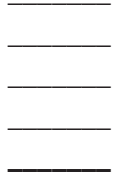

Valor da Pontuação

Valor da Pontuação

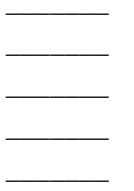

